\title{
Correlation Between Malpractice Litigation and Legislation Reform in Taiwan Over a 30-Year Period
}

\author{
Ming-Ta Hsieh (iD) ${ }^{1-3}$ \\ Li-Hui Lu ${ }^{2}$ \\ Chi-Wei Lin ${ }^{1,4}$ \\ Yun-Wen Chen ${ }^{5}$ \\ 'Department of Family Medicine and \\ Community Medicine, E-Da Hospital, \\ Kaohsiung City, Taiwan; ${ }^{2}$ College of Law, \\ National University of Kaohsiung, \\ Kaohsiung City, Taiwan; ${ }^{3}$ Department of \\ Nursing, College of Medicine, I-Shou \\ University, Kaohsiung City, Taiwan; \\ ${ }^{4}$ School of Medicine for International \\ Students, College of Medicine, I-Shou \\ University, Kaohsiung City, Taiwan; \\ ${ }^{5}$ Pediatrician, Local Clinic, Kaohsiung \\ City, Taiwan
}

Background: The annual medical litigation rate has increased yearly since 1987 in Taiwan. Policy makers keep going medical legislation reforms. The effectiveness of legislation reforms to reduce malpractice litigation risk is uncertain.

Objective: To determine whether medical legislation reform helps reduce the risk of medical litigation.

Design, Setting, and Participants: This retrospective study used national data obtained from Ministry of Health and Welfare in Taiwan. The period analyzed was from 1987 to 2018. The annual medical litigation rate was determined, types of medical negligence litigation were compared, medical appraisal results were summarized, and the importance of medical legislation was identified.

Interventions: After legislation reform vs before legislation reform.

Measurements: The main outcome showed trends in medical dispute assessments over time by adjusting for the general population (per 1,000, 000 people). We established 2004 and 2012 as the 2 cut-points for further analysis of medical appraisal results due to legislation reform.

Results: With legislation reforms, the annual medical litigation rate decreased from 26.68 cases per million people in 2012 to 16.41 cases per million people in 2018 . The annual medical litigation rate declined by approximately 38\% from 2012 to 2018. Medical appraisal results were malpractice cases in $22.1 \%$ before Medical Care Act (2004 Reform) compared with $18.8 \%$ from 2004 to 2012 (odds ratio [OR], 0.82; 95\% CI, $0.727-0.924 ; \mathrm{p}=0.001$ ), and $6.4 \%$ after mediation system introduced in 2012 (odds ratio [OR], 0.243; 95\% CI, 0.205-0.288; $<<0.001$ ).

Conclusion: Medical legislation reform has reduced the risk of malpractice litigation over time.

Keywords: medical malpractice, medical legislation reform, health policy

\section{Introduction}

During the COVID-19 pandemic, public health systems have played a crucial role in numerous countries and indicated a nation's capacity to respond to outbreaks, protect high-risk populations, limit community spread, and provide vaccines or other novel therapeutic approaches. $^{1-5}$ The National Health Insurance system, a single-payer insurance system that covers virtually the entire population of Taiwan, has covered the provision of medical services since 1995. ${ }^{6,7}$ Numerous patients have received advanced medical services from the public health system since its establishment.
Correspondence: Ming-Ta Hsieh Department of Family Medicine and Community Medicine, E-Da Hospital, No.

I, Yida Road, Jiao-su Village, Yan-chao

District, Kaohsiung City, 82445, Taiwan

Email kaplan210@yahoo.com.tw 
However, although people may focus on the public health system, they may neglect the efforts of medical staff. When conducting medical procedures, medical staff members are undoubtedly exposed to the risk of malpractice litigation. Therefore, medical legislation reforms regarding such litigation risk play an essential role in the public health system.

Medical disputes require respect for patient autonomy and are associated with the individual nature of the patient-physician relationship. ${ }^{8-10}$ Even taking into patients' emotions and idiosyncrasies, medical malpractice claims by patients remain high. The number of medical disputes is increasing daily. Regarding medical malpractice, Taiwan and the United States are different in the law evaluation circumstance. In the case law system country such as United States, the cost of malpractice insurance has skyrocketed in some specialties and geographic areas because of a medical liability crisis. ${ }^{11,12}$ The constant threat of litigation also drives many physicians to adopt a defensive medicine strategy, which entails performing extraneous and often inappropriate procedures. ${ }^{13-17}$ In defensive medicine, responses are undertaken primarily to avoid liability rather than to benefit the patient. Under medical liability crisis, defensive medicine is more than before. Because of such changes, medical legislation reform is necessary to avoid the collapse of the medical system. When the Medical Care Act was enacted in 1986 in Taiwan, the legal provisions for medical malpractice in Medical Care Act was not clearly stipulated. No-fault liability and fault liability were ambiguous at that time. In 2004, Medical Care Act (2004 Reform) excluded the application of no-fault liability and established the standards for medical negligence. In 2012, policy makers proposed the Medical Malpractice Resolution and Compensation Act (draft) as the alternative dispute resolution (ADR) system for medical litigations.

In this article, we analyze the correlation between malpractice litigation and medical legislation reform in Taiwan over a 30 -year period. This analysis provides evidence and information to policy makers so that the government can continue to reform medical legislation and improve the public health system.

\section{Methods}

\section{Medical Review Committee Assessment Report Review}

The medical dispute analysis detailed herein was based on public statistical data provided by the official Medical
Review Committee (MRC) of the Ministry of Health and Welfare in Taiwan. Observational studies regarding medical disputes were analyzed according to the year of completion to investigate trends in assessment reports over time during the study period. Data were collected for the period of 1987 to 2018 . The analysis was based on 3 major topics: medical dispute litigation type, medical appraisal results, and the annual medical litigation rate.

\section{Medical Dispute Litigation Type and Medical Appraisal Results}

Taiwan has a statutory law system like Japan and Germany, so some medical disputes will undergo criminal proceedings that may be different from case law countries. In Taiwan, medical dispute litigation types are mainly divided into civil and criminal cases. According to the MRC statistics, medical appraisal results can be divided into "negligence," "possible negligence," "no negligence," "unable to identify," "not a medical dispute," and "other." "No negligence" cases can also be referred to as "no-fault" cases, signifying that the medical staff exercised due care while conducting a medical procedure. However, "negligence" cases and "possible negligence" cases indicate that medical personnel did not meet the standard duty of care. "Unable to identify" cases indicate that the medical appraisers may have conflicting opinions regarding the case. "Other" indicates that the cases were revoked, withdrawn, or lacked clinical data.

\section{Trends Over Time Adjusted for the General Population}

The population of Taiwan has gradually increased since 1987. Data on the total population were based on statistics from Taiwan's Ministry of the Interior. On the basis of the annual medical litigation rate, we further analyzed trends in medical dispute assessments over time by adjusting for the general population (per 1,000,000 people).

\section{Statistical Analysis}

Medical dispute assessments were analyzed according to the year of completion and the result of the medical appraisal. The major reform of Medical Care Act (2004 Reform) is in Paragraph 2, Article 82. It revealed that "Medical care institutions and their medical personnel who harm patients in the execution of practice, whether deliberate or by accident, shall be responsible for compensation.“ 
The legal element is based on the negligence standard which excluded the application of no-fault liability at that time. In addition, the ADR system focuses on strengthening the mediation mechanism and quickly resolving disputes before going to the malpractice litigation. Because of the Medical Care Act (2004 Reform) and the ADR system introduced in 2012, we established 2004 and 2012 as the two cut-points for further analysis. Data were analyzed using SPSS version 27.0 (IBM).

\section{Results}

From 1987 to 2018, the MRC completed a total of 11,162 assessment reports, 10,737 of which involved medical malpractice, with the remaining 425 not involving medical malpractice. More criminal cases than civil cases were reported, and the total number of cases increased yearly from 1987. The number of medical disputes, whether civil or criminal, peaked in 2012 and subsequently began to decline (Figure 1). Over the years, criminal litigation accounted for $82.5 \%$ and civil litigation accounted for $17.5 \%$ of all medical litigation cases (Table 1). On average, the percentage of criminal cases was approximately 4.7 times higher than that of civil cases.
Excluding "not a medical dispute" revealed that the annual medical litigation rate decreased slightly from 19.44 cases per million people in 2004 to 16.38 cases per million people in 2005. However, the rate increased from 17.97 cases per million people in 2006 to 20.36 cases per million people in 2008, surpassing the previous high of 20.08 cases per million people in 2003 , and continued to increase slightly until 2012 (Table 1).

According to judicial data, the annual medical litigation rate increased from 6.69 cases per million people in 1987 to a peak of 26.68 cases per million people in 2012 and subsequently began to decline (Figure 2). The annual medical litigation rate in 2012 was approximately 3.99 times higher than that in 1987. With medical legislation reforms such as the establishment of legal elements in Medical Care Act (2004 Reform) and mediation system (2012), the annual medical litigation rate decreased from 26.68 cases per million people in 2012 to 16.41 cases per million people in 2018. The annual medical litigation rate declined by approximately 38\% from 2012 to 2018 . During this 30-year period, the annual medical litigation rate was approximately 14.82 cases per million people per year.

\section{Number of Criminal Litigation Cases and Civil Litigation Cases}

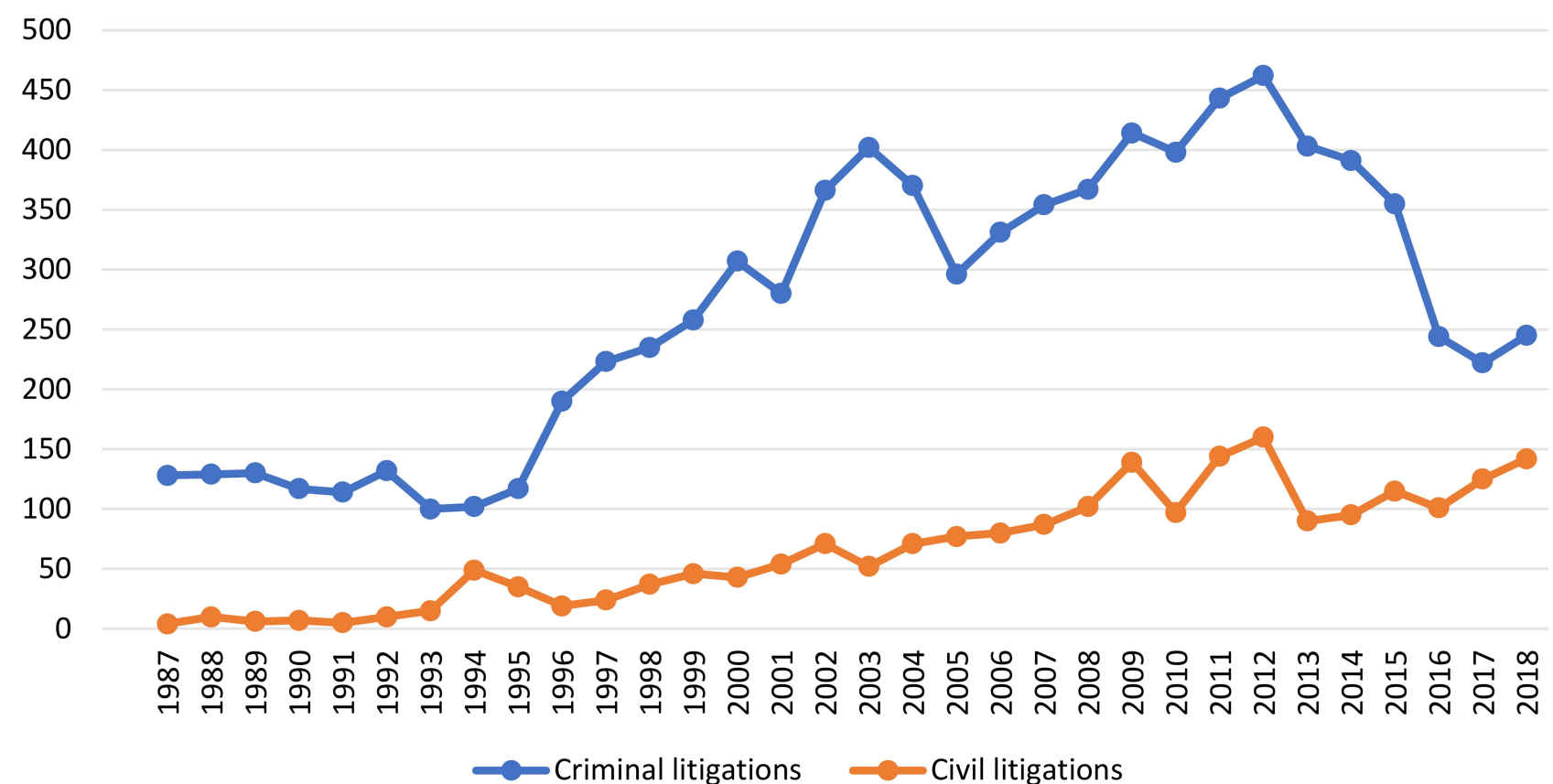

Figure I Number of Criminal and Civil Litigation Cases in Medical Disputes. The type of medical dispute litigation can mainly be divided into civil and criminal claims. The number of criminal litigation cases was higher than that of civil litigation cases. 
Table I Types of Medical Dispute Litigation and Rates of Annual Medical Litigation

\begin{tabular}{|c|c|c|c|c|c|c|c|c|c|}
\hline Year & $\begin{array}{l}\text { Criminal } \\
\text { Litigations }\end{array}$ & $\begin{array}{l}\text { Criminal } \\
\text { (\%) }\end{array}$ & $\begin{array}{l}\text { Civil } \\
\text { Litigations }\end{array}$ & $\begin{array}{l}\text { Civil } \\
\text { (\%) }\end{array}$ & $\begin{array}{l}\text { Medical } \\
\text { Litigations }\end{array}$ & Others & Total & $\begin{array}{c}\text { Total } \\
\text { Population }\end{array}$ & $\begin{array}{c}\text { The Medical Litigation } \\
\text { Rates (Per Million People) }\end{array}$ \\
\hline 1987 & 128 & 97 & 4 & 3 & 132 & 13 & 145 & $19,725,010$ & 6.69 \\
\hline 1988 & 129 & 92.8 & 10 & 7.2 & 139 & 24 & 163 & $19,954,397$ & 6.97 \\
\hline 1989 & 130 & 95.6 & 6 & 4.4 & 136 & 14 & 150 & $20,156,587$ & 6.75 \\
\hline 1990 & 117 & 94.4 & 7 & 5.6 & 124 & 3 & 127 & $20,40 \mathrm{I}, 305$ & 6.08 \\
\hline 1991 & 114 & 95.8 & 5 & 4.2 & 119 & 9 & 128 & $20,605,831$ & 5.78 \\
\hline 1992 & 132 & 93 & 10 & 7 & 142 & 23 & 165 & $20,802,622$ & 6.83 \\
\hline 1993 & 100 & 87 & 15 & 13 & 115 & 25 & 140 & $20,995,416$ & 5.48 \\
\hline 1994 & 102 & 67.5 & 49 & 32.5 & $|5|$ & 40 & 191 & $21,177,874$ & 7.13 \\
\hline 1995 & 117 & 77 & 35 & 23 & 152 & 42 & 194 & $21,357,431$ & 7.12 \\
\hline 1996 & 190 & 90.9 & 19 & 9.1 & 209 & 25 & 234 & $21,525,433$ & 9.71 \\
\hline 1997 & 223 & 90.3 & 24 & 9.7 & 247 & 13 & 260 & $21,742,815$ & 11.36 \\
\hline 1998 & 235 & 86.4 & 37 & 13.6 & 272 & 15 & 287 & $21,928,591$ & 12.40 \\
\hline 1999 & 258 & 84.9 & 46 & 15.1 & 304 & 28 & 332 & $22,092,387$ & 13.76 \\
\hline 2000 & 307 & 87.7 & 43 & 12.3 & 350 & 33 & 383 & $22,276,672$ & $|5.7|$ \\
\hline 2001 & 280 & 83.8 & 54 & 16.2 & 334 & 32 & 366 & $22,405,568$ & $14.9 \mid$ \\
\hline 2002 & 366 & 83.8 & 71 & 16.2 & 437 & 19 & 456 & $22,520,776$ & 19.4 \\
\hline 2003 & 402 & 88.5 & 52 & 11.5 & 454 & 11 & 465 & $22,604,550$ & 20.08 \\
\hline 2004 & 370 & 83.9 & 71 & 16.1 & 441 & 9 & 450 & $22,689,122$ & 19.44 \\
\hline 2005 & 296 & 79.4 & 77 & 20.6 & 373 & 3 & 376 & $22,770,383$ & 16.38 \\
\hline 2006 & 331 & 80.5 & 80 & 19.5 & 411 & 7 & 418 & $22,876,527$ & 17.97 \\
\hline 2007 & 354 & 80.3 & 87 & 19.7 & $44 I$ & 3 & 444 & $22,958,360$ & 19.21 \\
\hline 2008 & 367 & 78.3 & 102 & 21.7 & 469 & 3 & 472 & $23,037,031$ & 20.36 \\
\hline 2009 & 414 & 74.9 & 139 & 25.1 & 553 & 3 & 556 & $23,119,772$ & 23.92 \\
\hline 2010 & 398 & 80.4 & 97 & 19.6 & 495 & I & 496 & $23,162,123$ & 21.37 \\
\hline 2011 & 443 & 75.5 & 144 & 24.5 & 587 & I & 588 & $23,224,912$ & 25.27 \\
\hline 2012 & 462 & 74.3 & 160 & 25.7 & 622 & 1 & 623 & $23,3 \mid 5,822$ & 26.68 \\
\hline 2013 & 403 & 81.7 & 90 & 18.3 & 493 & 3 & 496 & $23,373,517$ & 21.09 \\
\hline 2014 & 391 & 80.5 & 95 & 19.5 & 486 & I & 487 & $23,433,753$ & 20.74 \\
\hline 2015 & 355 & 75.5 & 115 & 24.5 & 470 & 4 & 474 & $23,492,074$ & 20.01 \\
\hline 2016 & 244 & 70.7 & 101 & 29.3 & 345 & 6 & 351 & $23,539,816$ & 14.66 \\
\hline 2017 & 222 & 64 & 125 & 36 & 347 & 7 & 354 & $23,571,227$ & 14.72 \\
\hline 2018 & 245 & 63.3 & 142 & 36.7 & 387 & 4 & 391 & $23,588,932$ & 16.41 \\
\hline Average & & 82.5 & & 17.5 & & & & & 14.82 \\
\hline
\end{tabular}

In Taiwan, medical appraisal results are mainly used by a judge as a reference during the evaluation of evidence. For medical litigation, we focused on three groups: "negligence," "possible negligence," and "no negligence/no-fault. "The "negligence" and "possible negligence" cases were combined into the "malpractice" cases and compared with the "no negligence/no-fault" cases. Notably, "no-fault" cases were more frequent than "negligence" and "possible negligence" cases (Figure 3). "No-fault" cases accounted for approximately $68.1 \%$ of all MRC reports, and "negligence" and "possible negligence" cases accounted for approximately $15.3 \%$ of all MRC reports (Table 2). The percentage of "no-fault" cases was approximately 4.5 times higher than that of "negligence" and "possible negligence" cases.
We used the Medical Care Act (2004 Reform) as a cut-point for analyzing medical appraisal results. We then further compared the "malpractice" cases ("negligence" and "possible negligence" cases) and the "nofault" cases. Before Medical Care Act (2004 Reform), $22.1 \%$ of medical appraisals (751 cases) were "malpractice" cases, whereas from 2004 to $2012,18.8 \%$ of medical appraisals (609 cases) were "malpractice" cases (OR, 0.82; 95\% CI, 0.727-0.924; p=0.001) (Table 2). The percentage decreased, and Medical Care Act (2004 Reform) significantly affected medical appraisal results.

Evidently, the rate of annual medical lawsuits peaked in 2012. The total number of malpractice cases in Taiwan 


\section{The rate of annual medical litigation (per million people)}

30

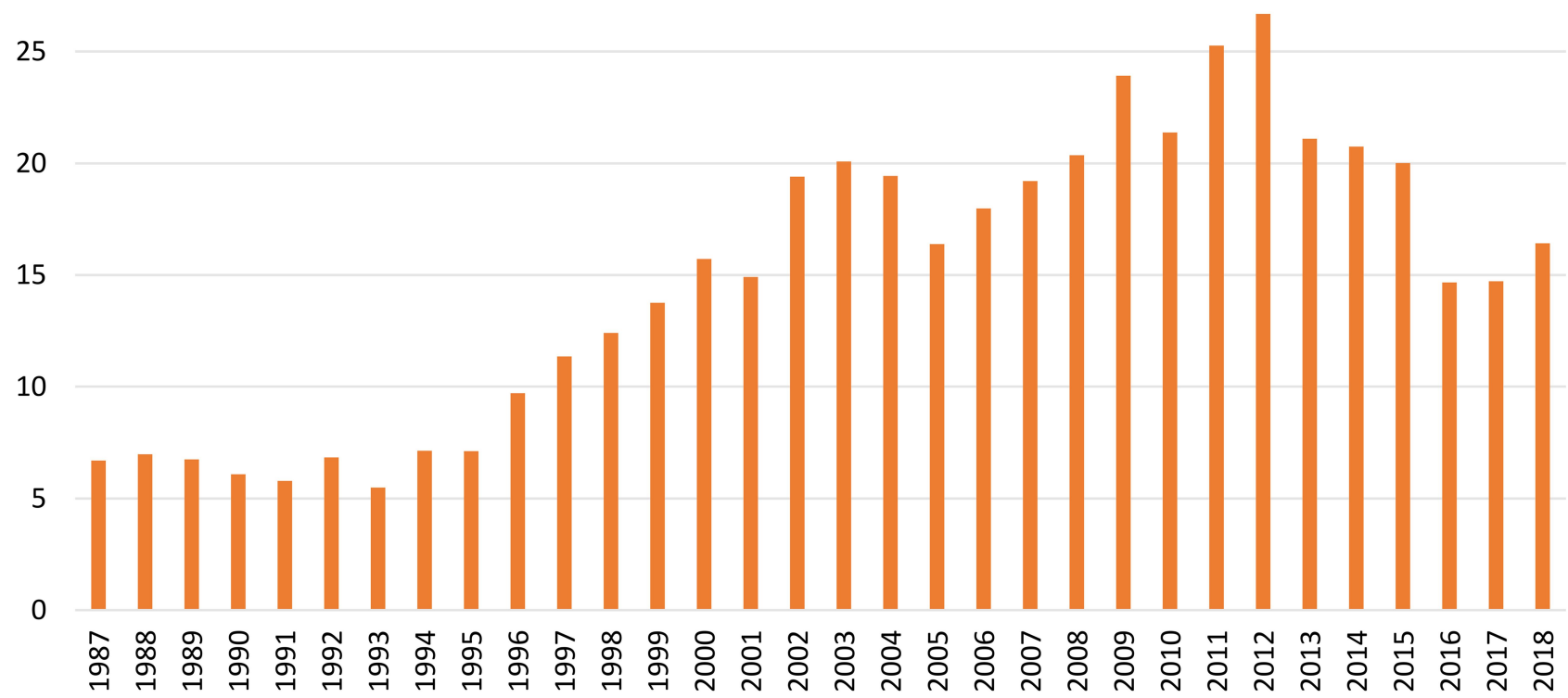

Figure 2 Trend in annual medical litigation rate. This figure displays the trend in the annual medical litigation rate (per million people) from 1987 to 2018.

\section{The Result of Medical Appraisal Cases}

600

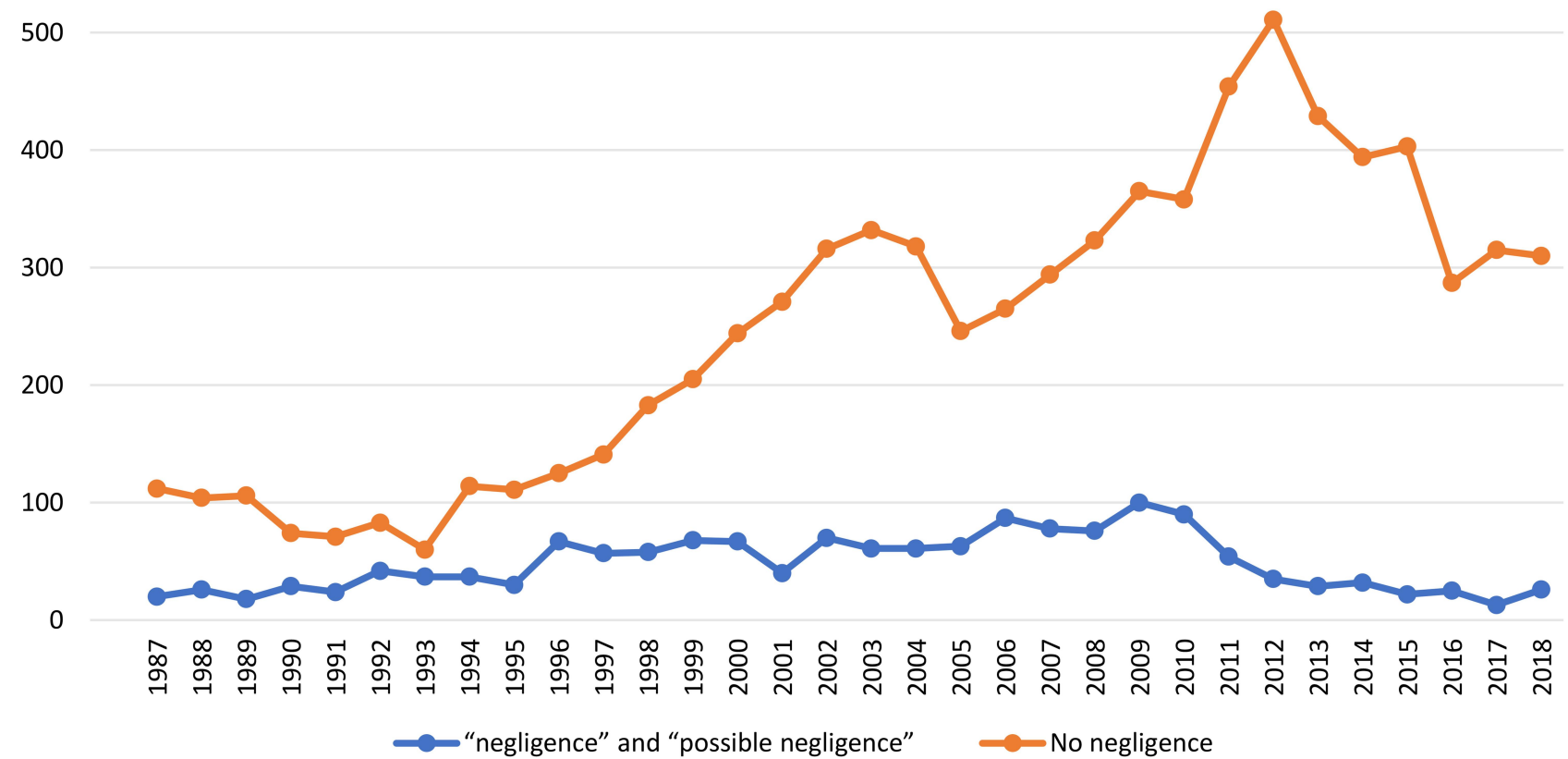

Figure 3 Results of medical appraisal. The number of "no-fault" cases was higher than that of "negligence" and "possible negligence" cases.

reached 622 that year, and the annual medical litigation rate reached 26.68 cases per million people in 2012. The Medical Malpractice Resolution and Compensation Act (draft) introduced the ADR system at that time for resolving such problems. Additionally, with the encouragement of the government, medical care institutions also began to 


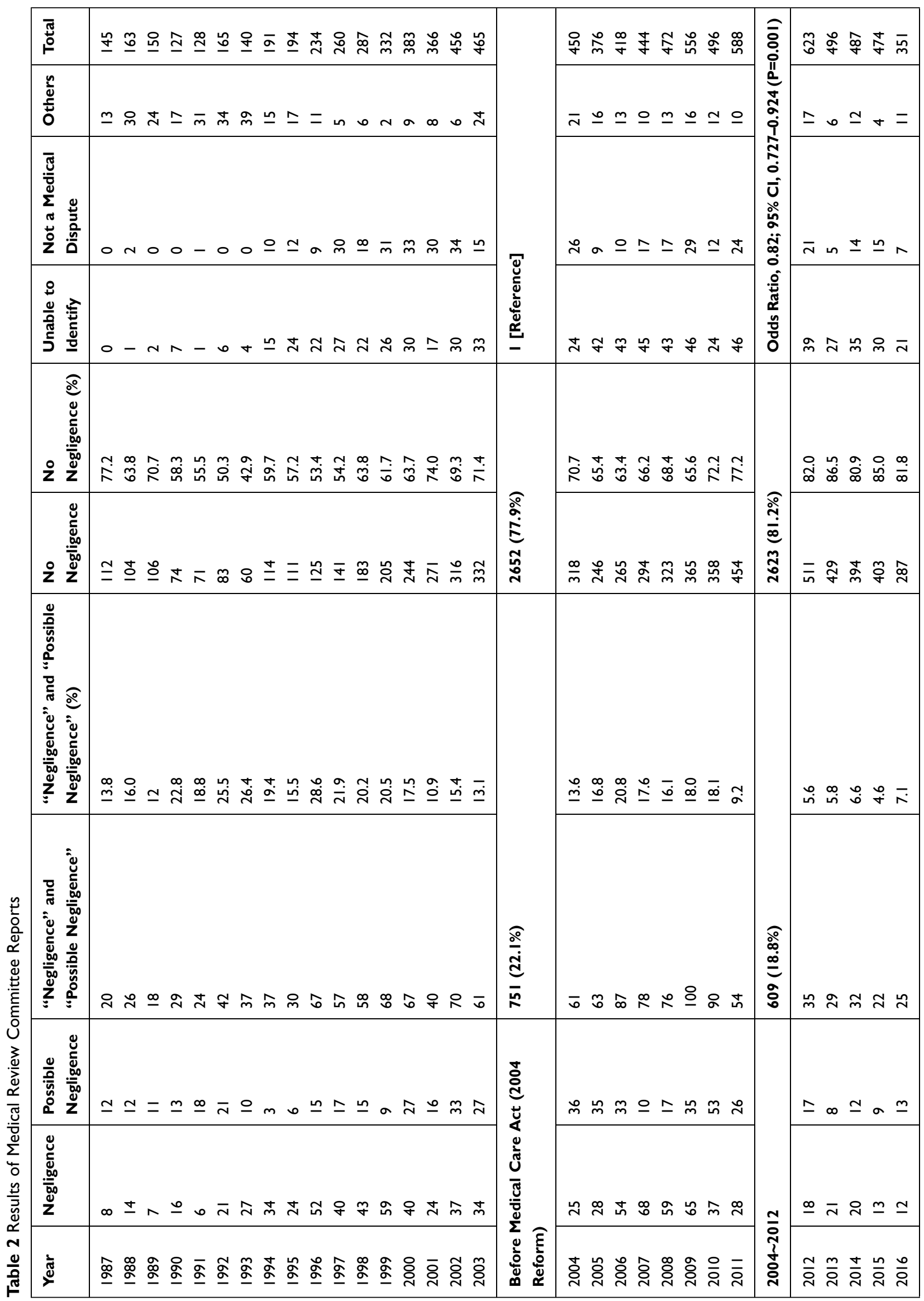




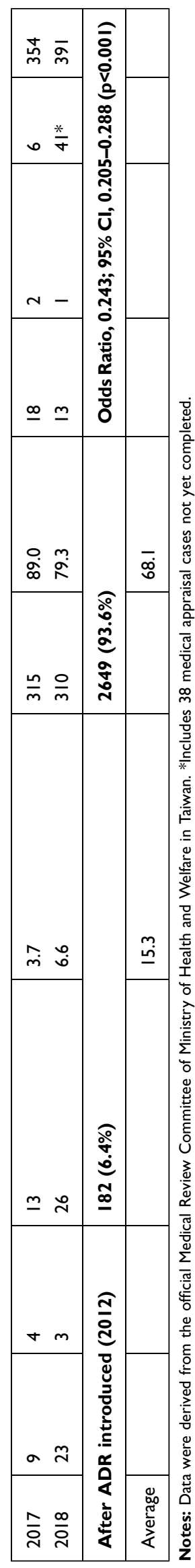

establish internal mediation systems to resolve medical disputes.

We also established 2012 as a cut-point for analyzing medical appraisal results. Before legislation reform, 22.1\% of medical appraisals (751 cases) were "malpractice" cases, whereas after mediation system was introduced in 2012, 6.4\% of medical appraisals (182 cases) were "malpractice" cases (OR, 0.243; 95\% CI, 0.205-0.288; $\mathrm{p}<0.001$ ) (Table 2). The percentage decreased and a significant correlation was observed between the introduction of the ADR system and medical appraisal results.

\section{Discussion}

In the current observational study, we analyzed nationwide assessment reports from the MRC and the Ministry of Health and Welfare over a 30-year period in Taiwan. We focused on three major topics: medical dispute litigation type, medical appraisal results, and the annual medical litigation rate.

As medical liability reform continues to progress, even if slowly, a better liability system that fosters progress toward safe, high-quality health care is expected to emerge. ${ }^{18-20}$ Taiwan has a statutory law system, and thus, medical legislation reform and legal elements were highly critical in the 30-year period studied. Over the study period, 2004 and 2012 represent two crucial time points. Medical legislation reform data were based on information provided by the Legislative Yuan, the central legislative body in Taiwan. The Medical Care Act (2004 Reform) explicitly excluded the application of no-fault liability described in the Consumer Protection Act, and the essence of its legal elements is based on the negligence standard in civil law. In 2012, the Executive Yuan (Taiwan) proposed the Medical Malpractice Resolution and Compensation Act (draft) to establish an ADR system for medical malpractice. Additionally, policy makers also advocated for internal mediation systems in medical care institutions and promoted communication between medical and legal professionals. The current study revealed five major findings.

First, in medical malpractice litigation in Taiwan, more criminal cases than civil cases were reported in the 30 -year period studied; this was largely due to the litigation strategies adopted by patient-plaintiffs in Taiwan. Victims tended to view using criminal proceedings as their optimal litigation strategy due to the intervention of a prosecutor. For medical staff, the mental stress of criminal liability is greater than that of civil liability. Malpractice claims also 
have various effects on physicians; for instance, they may stop practicing medicine or switch to smaller practice settings. ${ }^{21}$ Conceivably, the strategy of criminal proceedings and increasing criminal litigations prompted the Medical Care Act (2004 Reform) in Taiwan.

Second, the annual medical litigation rate was 6.69 cases per million people in 1987 and peaked at approximately 26.68 cases per million people in 2012 . The annual medical litigation rate began to decrease after 2012, with the latest figure being 16.41 cases per million people as of 2018. Our study revealed that malpractice litigation has increased since the late 20th century, which is comparable with the worldwide upward trend in malpractice litigation. In the United States, the number of malpractice suits started rising in a geometric fashion, more frivolous lawsuits were filed, and malpractice insurance premiums started rising, resulting in a malpractice crisis. ${ }^{22}$ The growth in malpractice litigation has also been noted in Asian countries such as Japan, China, and Malaysia. ${ }^{23-25}$

Third, the percentage of physicians who are found to have been negligent during medical practice is low according to MRC assessment reports. Even with a no-fault medical appraisal, the extended duration of litigation consumes a considerable amount of physicians' time and energy. Furthermore, resolution of malpractice claims requires time and affects physicians because of lost time and the added stress from extra work and a damaged reputation. ${ }^{26-28}$ Therefore, medical legislation reform is imperative in the early 21 st century.

Fourth, the annual medical litigation rate slightly decreased in 2004 and 2013 and declined by approximately $38 \%$ from 2012 to 2018 , which corresponds to the timing of Medical Care Act (2004 Reform) and the introduction of the ADR system. This decline reveals that medical legislation reform and legal element changes can considerably influence the annual medical litigation rate. Four legal elements must be proven in medical malpractice: a professional duty owed to the patient; breach of such duty; injury caused by the breach; and resulting damages. ${ }^{29,30}$ Breach of professional duty is the most critical legal element for courts in determining whether a physician has acted negligently in medical practice. ${ }^{31}$ In Taiwan, the Medical Care Act was reformed and adjusted on April 9, 2004. Paragraph 2, Article 82 of the Medical Care Act (2004 Reform) established the basis for civil negligence liability in malpractice litigation. Additionally, the ADR system and other internal mediation systems were introduced in 2012. The annual medical litigation rate did not decrease in 2012 but decreased the following year possibly because policy discussion requires substantial time, and consequently, statistics cannot immediately reflect implemented changes.

Fifth, we combined the medical legislation reform and medical appraisal result time points. Medical appraisal results revealed less malpractice cases after legislation reform. In the study, we established 2004 and 2012 as 2 cut-points for further analysis. Medical appraisal results were malpractice cases in $22.1 \%$ before Medical Care Act (2004 Reform) compared with $18.8 \%$ from 2004 to 2012 (Odds ratio [OR], 0.82; 95\% CI, 0.727-0.924; $\mathrm{p}=0.001$ ), and $6.4 \%$ after mediation system introduced in 2012 (Odds ratio [OR], 0.243; 95\% CI, 0.205-0.288; $\mathrm{p}<0.001$ ). This decline in malpractice cases reveals a significant correlation between medical legislation reform and medical appraisal results.

Other studies have revealed that physicians with certain high-risk specialties or other distinctive characteristics are targets of more malpractice claims. ${ }^{32-35}$ Reducing the risk of medical litigation is highly critical. In an atmosphere with low risk of litigation, medical staff can concentrate on fighting disease, especially in the context of a pandemic such as COVID-19. Physicians should be able to understand and measure how and where they have not performed their duty. ${ }^{36}$ In the context of medical disputes, numerous studies have focused on the details of professional duties such as the duty to inform, the duty of care, and the duty of confidentiality. ${ }^{37-41}$ However, our observational study revealed a special finding. In addition to physicians understanding their professional duty, policy makers also play a crucial role in malpractice litigation. Legislation reform and extensive discussions have not only helped reduce the number of medical lawsuits but have also affected medical appraisal results. Consequently, a statistically significant reduction in negligence results was observed.

In the 30-year period studied, physicians in Taiwan confronted an array of immediate challenges associated with the increasing number of malpractice claims. Similar to judges in continental European countries, judges in Taiwan independently investigate the facts of a case and decide the outcome. Therefore, reforming the Medical Care Act remains a priority because it is the applicable regulation for medical malpractice. Legislation reform makes the legal elements clearer than before. This protects the rights and harmonious relationship between patients 
and medical staff. Patient can also receive fair trial form judges under clear legal elements in statutory law country.

Medical legislation reform in Taiwan is consistent with international trends. Countries that use case law also appear to reform their common law of torts related to medical malpractice. ${ }^{42-44}$ Additionally, the ADR system may be regarded as a means for resolving medical disputes, reflecting the examples of other countries. ${ }^{45-48}$ As the rights of medical staff began to take priority, the annual medical litigation rate gradually decreased. Medical legislation reform significantly progressed toward resolving the increasing number of malpractice claims in Taiwan in the 30-year period studied.

\section{Limitations}

This study has several limitations. It was restricted to the variables and factors for which data were available, including high-risk specialties, distinctive characteristics, patient's clinical condition, patient-physician relationship and physicians perform their duty or not. Although the statistical analysis of odds ratio reveals that legislation reform plays an important role in reducing the risk of malpractice litigation, this study may be limited by differences between statutory law and case law in different countries. The results obtained can be generalized to countries with statutory law system similar to Taiwan's. Nonetheless, caution should be exercised in generalizing them to other countries with case law system.

\section{Conclusion}

According to the current observational study, the annual medical litigation rate gradually increased since 1987, and of malpractice claims, more criminal cases were filed than civil cases. After the Medical Care Act (2004 Reform) and the introduction of the ADR system, the annual medical litigation rate decreased. Among medical appraisal results, more "no negligence" cases were reported than "negligence" and "possible negligence" cases. A significant correlation was also observed between medical legislation reform and medical appraisal results. Legislation reform progress in Taiwan demonstrates that consensus in society, belief in communication, and courage to change can help establish a better health care system.

\section{Human Participant Protection Statement}

No human participant in this research.

\section{Disclosure}

All authors declare that: (i) no support, financial or otherwise, has been received from any organization that may have an interest in the submitted work; and (ii) there are no other relationships or activities that could appear to have influenced the submitted work.

\section{References}

1. Bauchner H, Sharfstein J. A bold response to the COVID-19 pandemic: medical students, national service, and public health. JAMA. 2020;323:1790-1791. doi:10.1001/jama.2020.6166

2. Lin C, Braund WE, Auerbach J, et al. Policy decisions and use of information technology to fight COVID-19, Taiwan. Emerg Infect Dis. 2020;26:1506-1512. doi:10.3201/eid2607.200574

3. Pollard CA, Morran MP, Nestor-Kalinoski AL. The COVID-19 pandemic: a global health crisis. Physiol Genomics. 2020;52:549-557. doi:10.1152/physiolgenomics.00089.2020

4. Wang J, Peng Y, Xu H, Cui Z, Williams RO. The COVID-19 vaccine race: challenges and opportunities in vaccine formulation. AAPS PharmSciTech. 2020;21:225. doi:10.1208/s12249-020-01744-7

5. Polack FP, Thomas SJ, Kitchin N, et al. Safety and efficacy of the BNT162b2 mRNA Covid-19 vaccine. $N$ Engl $J$ Med. 2020;383:2603-2615. doi:10.1056/NEJMoa2034577

6. Reinhardt UE. Humbled in Taiwan. BMJ. 2008;336:72. doi:10.1136/ bmj.39450.473380.0F

7. Lang HC, Lai MS. Willingness to pay to sustain and expand National Health Insurance services in Taiwan. BMC Health Serv Res. 2008;8:261. doi:10.1186/1472-6963-8-261

8. Amirthalingam K. Medical dispute resolution, patient safety and the doctor-patient relationship. Singapore Med J. 2017;58:681-684. doi:10.11622/smedj.2017073

9. Shouhed D, Beni C, Manguso N, IsHak WW, Gewertz BL. Association of emotional intelligence with malpractice claims: a review. JAMA Surg. 2019;154:250-256. doi:10.1001/jamasurg.2018.5065

10. Levinson W, Roter DL, Mullooly JP, Dull VT, Frankel RM. Physician-patient communication. The relationship with malpractice claims among primary care physicians and surgeons. JAMA. 1997;277:553-559. doi:10.1001/jama.1997.03540310051034

11. Struve CT. Improving the medical malpractice litigation process. Health Aff (Millwood). 2004;23:33-41. doi:10.1377/hlthaff.23.4.33

12. Sataloff J. The first step toward stopping the malpractice insurance crisis. Ear Nose Throat J. 2008;87:492-494. doi:10.1177/014556130808700902

13. Hatch SOG. Invited commentary-it is time to address the costs of defensive medicine: comment on "physicians' views on defensive medicine: a national survey". Arch Intern Med. 2010;170:1081-1083. doi:10.1001/archinternmed.2010.155.1

14. Bishop TF, Federman AD, Keyhani S. Physicians' views on defensive medicine: a national survey. Arch Intern Med. 2010;170:1081-1083.

15. Dove JT, Brush JE, Chazal RA, Oetgen WJ. Medical professional liability and health care system reform. $J$ Am Coll Cardiol. 2010;55:2801-2803. doi:10.1016/j.jacc.2010.03.028

16. Nahed BV, Babu MA, Smith TR, Heary RF. Malpractice liability and defensive medicine: a national survey of neurosurgeons. PLoS One. 2012;7:e39237. doi:10.1371/journal.pone.0039237

17. Studdert DM, Mello MM, Sage WM, et al. Defensive medicine among high-risk specialist physicians in a volatile malpractice environment. JAMA. 2005;293:2609-2617. doi:10.1001/jama.293.21.2609

18. Kachalia A, Mello MM. New directions in medical liability reform. N Engl J Med. 2011;364:1564-1572. doi:10.1056/NEJMhpr1012821

19. Mello MM, Kachalia A, Studdert DM. Medical liability - prospects for federal reform. N Engl J Med. 2017;376:1806-1808. doi:10.1056/ NEJMp 1701174 
20. Parekh A, Hoagland GW. Medical liability reform in a new political environment. JAMA. 2017;317:1311-1312. doi:10.1001/jama.2017. 1405

21. Studdert DM, Spittal MJ, Zhang Y, Wilkinson DS, Singh H, Mello MM. Changes in practice among physicians with malpractice claims. $N$ Engl J Med. 2019;380:1247-1255. doi:10.1056/NEJMsa 1809981

22. Berlin L. Medical errors, malpractice, and defensive medicine: an ill-fated triad. Diagnosis (Berl). 2017;4:133-139. doi:10.1515/dx2017-0007

23. Hamasaki T, Takehara T, Hagihara A. Physicians' communication skills with patients and legal liability in decided medical malpractice litigation cases in Japan. BMC Fam Pract. 2008;9:43. doi:10.1186/ 1471-2296-9-43

24. Wang Z, Li N, Jiang M, Dear K, Hsieh CR. Records of medical malpractice litigation: a potential indicator of health-care quality in China. Bull World Health Organ. 2017;95:430-436. doi:10.2471/ BLT.16.179143

25. Hambali SN, Khodapanahandeh S. A review of medical malpractice issues in Malaysia under tort litigation system. Glob J Health Sci. 2014;6:76-83. doi:10.5539/gjhs.v6n4p76

26. Jena AB, Chandra A, Lakdawalla D, Seabury S. Outcomes of medical malpractice litigation against US physicians. Arch Intern Med. 2012;172:892-894. doi:10.1001/archinternmed.2012.1416

27. Hwang CY, Wu CH, Cheng FC, Yen YL, Wu KH. A 12-year analysis of closed medical malpractice claims of the Taiwan civil court: a retrospective study. Medicine (Baltimore). 2018;97:e0237. doi:10.1097/MD.0000000000010237

28. Seabury SA, Chandra A, Lakdawalla DN, Jena AB. On average, physicians spend nearly 11 percent of their 40-year careers with an open, unresolved malpractice claim. Health Aff (Millwood). 2013;32:111-119. doi:10.1377/hlthaff.2012.0967

29. Bal BS. An introduction to medical malpractice in the United States. Clin Orthop Relat Res. 2009;467:339-347. doi:10.1007/s11999-0080636-2

30. Hudson MJ, Moore GP. Defenses to malpractice: what every emergency physician should know. J Emerg Med. 2011;41:598-606. doi:10.1016/j.jemermed.2010.07.001

31. Morris C, Chawla G, Francis T. Clinical negligence: duty and breach. Br Dent J. 2019;226:647-648. doi:10.1038/s41415-019-0312-9

32. Chen KY, Yang CM, Tsai SH, Chiou HY, Lin MR, Chiu WT. Medical malpractice in Taiwan: injury types, compensation, and specialty risk. Acad Emerg Med. 2012;19:598-600. doi:10.1111/j.1553-2712.2012. 01360.x

33. Studdert DM, Bismark MM, Mello MM, Singh H, Spittal MJ. Prevalence and characteristics of physicians prone to malpractice claims. $N$ Engl J Med. 2016;374:354-362. doi:10.1056/NEJMsa 1506137
34. Elsamadicy AA, Sergesketter AR, Frakes MD, Lad SP. Review of neurosurgery medical professional liability claims in the United States. Neurosurgery. 2018;83:997-1006. doi:10.1093/neuros/nyx565

35. Carroll AE, Buddenbaum JL. High and low-risk specialties experience with the U.S. medical malpractice system. BMC Health Serv Res. 2013;13:465. doi:10.1186/1472-6963-13-465

36. Mills MD. Learning from malpractice litigation. JAMA Ophthalmol. 2016;134:1235-1236. doi:10.1001/jamaophthalmol.2016.2981

37. Hamasaki T, Hagihara A. Physicians' explanatory behaviours and legal liability in decided medical malpractice litigation cases in Japan. BMC Med Ethics. 2011;12:7. doi:10.1186/1472-6939-12-7

38. Samuels A. The doctor's duty of confidentiality. Med Leg J. 2015;83:167-171. doi:10.1177/0025817215608982

39. Kloss D. The duty of care: medical negligence. Br Med J (Clin Res Ed). 1984;289:66-68. doi:10.1136/bmj.289.6436.66

40. Callier S, Simpson R. Genetic diseases and the duty to disclose. Virtual Mentor. 2012;14:640-644. doi:10.1001/virtualmentor.20 12.14.8.hlaw1-1208

41. Ferris LE, Barkun H, Carlisle J, Hoffman B, Katz C, Silverman M. Defining the physician's duty to warn: consensus statement of Ontario's medical expert panel on duty to inform. Cmaj. 1998;158:1473-1479.

42. Kessler DP, Summerton N, Graham JR. Effects of the medical liability system in Australia, the UK, and the USA. Lancet. 2006;368:240-246. doi:10.1016/S0140-6736(06)69045-4

43. Litvin SG. An overview of medical malpractice litigation and the perceived crisis. Clin Orthop Relat Res. 2005;8-14. doi:10.1097/01. blo.0000160019.12596.6f

44. Floyd TK. Medical malpractice: trends in litigation. Gastroenterology. 2008;134:1822-1825, 25.e1. doi:10.1053/j.gastro. 2008.05.001

45. Sohn DH, Bal BS. Medical malpractice reform: the role of alternative dispute resolution. Clin Orthop Relat Res. 2012;470:1370-1378. doi:10.1007/s11999-011-2206-2

46. American Arbitration Association. Healthcare Due Process Protocol; July 27, 1998. Available from: https://www.adr.org/sites/default/files/ document_repository/Healthcare-Due-Process-Protocol.pdf. Accessed March 1, 2021.

47. Alkhenizan AH, Shafiq MR. The process of litigation for medical errors in Saudi Arabia and the United Kingdom. Saudi Med J. 2018;39:1075-1081. doi:10.15537/smj.2018.11.22854

48. Wang M, Liu GG, Zhao H, Butt T, Yang M, Cui Y. The role of mediation in solving medical disputes in China. BMC Health Serv Res. 2020;20:225. doi:10.1186/s12913-020-5044-7
International Journal of General Medicine

\section{Publish your work in this journal}

The International Journal of General Medicine is an international, peer-reviewed open-access journal that focuses on general and internal medicine, pathogenesis, epidemiology, diagnosis, monitoring and treatment protocols. The journal is characterized by the rapid reporting of reviews, original research and clinical studies across all disease areas. The manuscript management system is completely online and includes a very quick and fair peer-review system, which is all easy to use. Visit http://www.dovepress.com/ testimonials.php to read real quotes from published authors. 